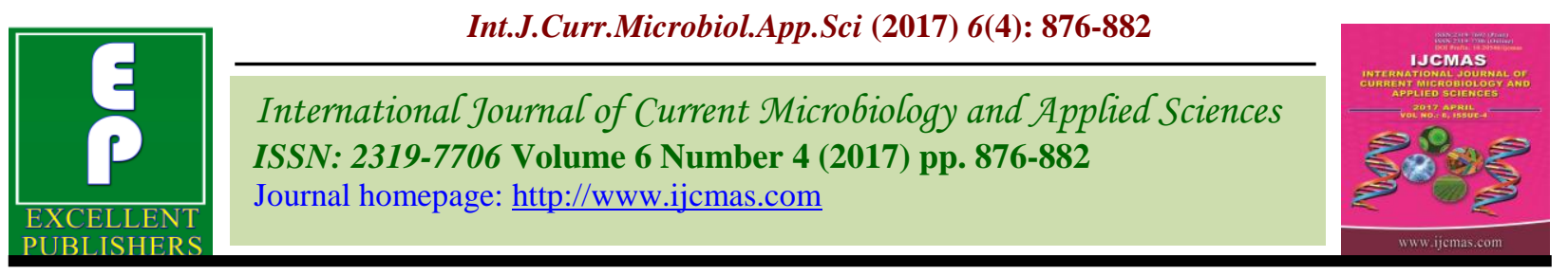

Review Article

https://doi.org/10.20546/ijcmas.2017.604.110

\title{
Melamine: A Monster in the Milk
}

\author{
Sachin S. Lad* and K.D. Aparnathi \\ Dairy Chemistry Department, SMC College of Dairy Science, AAU Anand-388110, India \\ *Corresponding author
}

\begin{tabular}{|c|c|}
\hline & A B S T R A C T \\
\hline $\begin{array}{l}\text { Melamine, } \\
\text { 1,3,5-triazine- } \\
\text { 2,4,6-triamine }\end{array}$ & \multirow{3}{*}{$\begin{array}{l}\text { Melamine is a versatile organic compound that has several industrial } \\
\text { applications. This industrial chemical is widely used to produce polymer by } \\
\text { reaction with formaldehyde. It is employed in manufacture of plastic, } \\
\text { laminates, wares, floors and table tops, paints, adhesives, permanent-press } \\
\text { fabrics, moulded furniture, foams and mattresses. It is also used as flame } \\
\text { retardant, colorant in inks, concrete plasticizers, paper finishing, tarnish } \\
\text { inhibitor, paper coating, textile finishes. However, in last decade this } \\
\text { versatile industrial chemical emerged as a potential adulterant in protein } \\
\text { rich feed, food and related ingredients and became serious threat to human } \\
\text { health. }\end{array}$} \\
\hline Article Info & \\
\hline $\begin{array}{l}\text { Accepted: } \\
\text { 06 March } 2017 \\
\text { Available Online: } \\
10 \text { April } 2017\end{array}$ & \\
\hline
\end{tabular}

\section{Introduction}

Melamine is a versatileorganic compound that has several industrial applications. This industrial chemical is widely used to produce polymer by reaction with formaldehyde. It is employed in manufacture of plastic, laminates, wares, floors and table tops, paints, adhesives, permanent-press fabrics, moulded furniture, foams and mattresses. It is also used as flame retardant, colorant in inks, concrete plasticizers, paper finishing, tarnish inhibitor, paper coating, textile finishes. However, in last decade this versatile industrial chemical emerged as a potential adulterant in protein rich feed, food and related ingredients andbecame serious threat to human health.

\section{Chemistry}

Melamine is a nitrogen-rich compound with molecular formula of $\mathrm{C}_{3} \mathrm{H}_{6} \mathrm{~N}_{6}$. IUPAC name of melamine is 1,3,5-triazine-2,4,6-triamine. From six atoms of nitrogen in the molecule, three atoms are present in amino groups and three atoms as a part of herocyclic ring.<smiles>Nc1nc(N)nc(N)n1</smiles>

Melamine 
The melamine is white, tasteless and odourless compound. It is a small polar molecule with a molecular weight of $126.12 \mathrm{~g}$ per mole. The nitrogen atoms constitute 66.67 per cent of the molecular weight of melamine. It is slightly soluble in water at $20^{\circ} \mathrm{C}(\sim 3.1$ $\mathrm{g} / \mathrm{l})$.

One of the remarkable characteristics of melamine is formation of crystals due to its extensive multiple hydrogen bonding. The structure of melamine, with its three $\mathrm{N}$ atoms in ring and three amino groups, enables the melamine to act as both a donor and acceptor in formation of hydrogenbonds, which enable its molecule to form extensive hydrogen bonds with cyanuric acid and biomolecules such as uracil, riboflavin, barbituric acid and uric acid.

Melamine crystal forms spoke-like crystals. The insoluble melamine complex in kidney causes renal disease by blocking up kidney tubules, preventing effective filtration of urine and/or damaging tubules by tubular dilatation and cutting walls of tubules, which in turn leads to bleeding.

\section{Safety aspects}

Melamine is not a natural product and is not approved for direct addition to food or feed. Studies concerning the toxicity of melamine taken orally in humans are not available. Toxicity data mainly come from studies in sheep, cat, dog, mice, and rat. Toxicity can be classified as acute or chronic. The most common toxicity is renal toxicity, which is also the area of most concern to nephrologists.

Melamine is not metabolized by animals and is rapidly absorbed from the gastrointestinal tract and eliminated in the urine. When male Fischer rats were fed $1.3 \mathrm{mg}$ melamine $/ \mathrm{kg}$ body weight within the first 24 hours about
$90 \%$ of the ingested melamine was excreted via urine. After $96 \mathrm{~h}$ from ingestion, the total excretion was $93 \%$ in urine.

In the pig, the melamine plasma half-life is approximately $4 \mathrm{~h}$. In general, melamine and cyanuric acid are not acute toxic because of their large lethal doses. The $\mathrm{LD}_{50}$, the toxic dose, of melamine in rats was $3296 \mathrm{mg} / \mathrm{kg}$ body weight and $7940 \mathrm{mg} / \mathrm{kg}$ bogy weight for cyanuric acid. Oral ingestion affects the digestive tract, presenting as nausea, vomiting, and diarrhea.

Long-term exposure to melamine reduces fertility and results in fetal toxicity in animal studies. In chronic exposure to melamine in dogs by feeding them $3 \%$ melamine by weight in food for 1 year, changes in specific gravity of urine, melamine crystalluria and proteinuria with microscopic hematuria were noted. The most commonly reported chronic renal toxicity is stone formation. The main toxic effects of melamine in rats and mice are urinary bladder hyperplasia, calculi formation and inflammatory reactions. Melamine at 800 $\mathrm{mg} / \mathrm{kg}$ caused significant nephrotoxicity, as evidenced by increased kidney weight and renal histopathological signs.

The World Health Organization (WHO) in September 2008 reported toxicity, preliminary risk assessment and guidance on levels of melamine in food. In collaboration with the Food and Agriculture Organization (FAO) supported by Health Canada, WHO conducted an expert meeting to review toxicological aspects of melamine and cyanuric acid in December 2008. The Codex Alimentarius Committee (CAC) has promulgated the maximum limits of $1 \mathrm{mg} / \mathrm{kg}$ in powdered infant formula and $2.5 \mathrm{mg} / \mathrm{kg}$ in food (other than infant formula) and feed in 2010 , and $0.15 \mathrm{mg} / \mathrm{kg}$ for melamine in liquid infant formula finally adopted in 2012.The melamine-contamination incidents prompted 
the US Food and Drug Administration (FDA), the European Community (EC) and other countries and regions to establish the criteria of Maximum Residue Limits (MRLs) for melamine in various food products used every day. The most common melamine limits established by different countries were $1 \mathrm{mg} / \mathrm{kg}$ for infant formula and $2.5 \mathrm{mg} / \mathrm{kg}$ for other milk and milk-based foods or all other foods.

The FSSAI has added a new regulation on melamine in milk and milk products through its notification dated 5th January, 2016. According to the amendment a new section has been added to the regulation called 'Other contaminants' in the Food Safety and Standards (Contaminants, toxins and Residues) Regulations, 2011. The new amended regulations will now be called the Food Safety and Standards (Contaminants, toxins and Residues) Amendment Regulations, 2016.The maximum limits of melamine content are $0.15 \mathrm{mg} / \mathrm{kg}$ in liquid infant formula, $1 \mathrm{mg} / \mathrm{kg}$ in powdered infant formula and $2.5 \mathrm{mg} / \mathrm{kg}$ in other food.

\section{Health hazards}

Melamine is described as being harmful if swallowed or inhaled. Direct contact results in skin irritation and eye irritation, and inhalation causes respiratory tract irritation. Oral ingestion affects the digestive tract, presenting as nausea, vomiting, and diarrhoea. In pets affected by melamine tainted food or ingestion of melamine and cyanuric acid, clinical symptoms were lethargy, anorexia, rough hair, dull fur, piloerection, reddish tears, nasal discharge, oral ulcers, reduction in food and water intake and reduction body weight gain. The biochemical diagnosis suggested high blood urea nitrogen and creatinine levels and low urine $\mathrm{pH}$. Histopathology of the kidneys of animals that died as the result of renal failure had yellowish-brown crystals present in the tubules.

The most reported target for melamine or melamine-cyanuric acid toxicity is kidney both humans and animals. Renal disease involves the formation of kidney stones or other small crystalluria inside the kidney tubules, which can lead to internal bleeding, kidney tubule blockage and/ or kidney failure. Kidney failure can occur from the blockage of the kidney tubules or the urinary tract, which effectively halts the detoxifying process that occurs inside the kidney. As time goes on, toxins and waste products normally extracted in the kidney will pile up, which leads to reduced blood flow to the kidney. This results in pain, poisoning, renal failure, and death. Crystals can also cause serious internal bleeding by damaging the walls of the kidney, ureter, and urethra.

Now findings from different studies imply that melamine toxicity is not limited to the urinary system only. It is also systemically cytotoxic to many different cell types in animals. The recent in vitro studies indicated that the toxicity of melamine with or without cyanuric acid might not be limited to the kidney, it is systemically cytotoxic to many different cell types in other parts of animal body, including central nervous system, reproductive system of male and female, visceral organs (liver, heart, stomach, small intestine, and the corpuscle of Stannius, human erythrocyte, spleen lymphocytes and skin. Even can pass through the placental barrier and results in to in utero transfer of melamine to foetus, following the maternal ingestion and causes toxicity to developing embryo and foetus. Triazine molecules are able to enhance the concentration of reactive oxygen species and may induce peroxidative damage to membrane lipids. It produces bladder tumours in rats at high dosages by a non-DNA reactive mechanism involving 
epithelial hyperplasia secondary to the presence of melamine-containing bladder stones.

\section{Sources in human food chain}

Melamine and its analogues enter into human food chain from a number of different sources, both dietary and environmental. The sources of melamine in food have been divided into two types as contamination and adulteration. The contamination is refer to as "baseline" levels, resulting from inevitable migration of melamine from environment to food or feed. The adulteration refers to as intentional illegal addition or misuse of melamine to food or feed. Baseline concentrations of melamine are present in the environment and in the food chain as a result of the widespread use of materials that contain melamine. Generally, baseline levels are expected to be $<1 \mathrm{mg} / \mathrm{kg}$ and these levels are not considered to be a health concern.

The very high nitrogen content makes melamine an attractive adulterant for protein rich feed and foodstuffs. As per the standard (AOAC) method the protein content of feeds and foods is estimated from its nitrogen content. This method directly does not measure the protein content. Generally, in protein analysis it is not fractionated from the food, prior to determination of nitrogen by Kjeldahl method, owing to very complex nature of food. This limitation of the method encourages the fraudulent addition of NPN compounds in food to elevate its apparent protein content.

Adulteration of feed and food ingredients with melamine and derivatives has been practiced worldwide for past 40 years. The use of melamine as an adulterant for high protein content ingredients can be traced back to the 1970s. The first case of melamine adulteration was detected in fish meals from
Italy during the late 1970s and potato meal for protein was found adulterated with melamine in Germany.

Three large scale incidences of using melamine as an adulterant in food and related ingredient occurred during last decade. The first incidence was in South-eastern Asian countries in which large outbreaks of nephrotoxic renal failure, occurred in dogs and cats during late 2003 and 2004,later on its cause correlated melamine contaminated pet food. In early 2007 very large outbreak of pet food-associated nephrotoxic renal failure and deaths of thousands of cats and dogs occurred in the North America. Veterinary scientists attributed the pet deaths to the nephropathy induced by crystals containing melamine and cyanuric acid present in the kidney. Another outbreak occurred in 2008, this time victims were infants and young children. Thousands of infants were rushed to hospital with symptoms of crying and internal bleeding. Again melamine was found as culprit. The Chinese government reported that 294000 babies had fallen ill, 51900 were hospitalized and 6 died, after consuming melamine-tainted infant formula. The children in other parts of Asia such as Taiwan, Singapore and Vietnam were also affected.

In 2008 observations on melamine found in some South African milk products suggested that melamine transfers from feed to milk. When cows consumed the melamine adulterated feed, melamine appeared in their milk as early as 8 hours after the first consumption. When cows were withdrawn from the melamine diet, the melamine persisted in the milk for up to 7 days afterwards. The other studies also investigated the transfer efficiency of melamine from feed to milk of lactating cows.

When melamine-contaminated milk is converted to milk powder, the melamine level 
would be concentrated approximately 8-fold. Therefore, if raw milk contaminated with melamine at $0.125 \mathrm{mg} / \mathrm{kg}$ or $0.3125 \mathrm{mg} / \mathrm{kg}$ were used to produce infant formula powder and common milk powder, the melamine content would reach the respective maximum allowable levels of infant formula powder and common milk powder. The cheese-making process showed that melamine is almost entirely transferred to whey.

During the process of making cheese with melamine tainted milk, melamine was predominantly partitioned to whey $(97.4 \%)$ with little transmission to cheese $(6.5 \%)$. Since, maternal transfer of melamine through breast-feeding is possible way of introduction, maternal transfer of melamine into breast milk through oral intake by lactating rats was evaluated. In the lactating rats, about $40 \%$ of maternal intake of melamine was transferred to breast milk and peaked at $3 \mathrm{~h}$. For health of the babies and young children, lactating mothers should avoid exposure to melaminecontaminated foods.

Milk powder is one of the most widely traded food commodities and is used in a huge array of food products, from infant formula to baked goods and confectionary. Soon after the incident of infant formula, melamine was found in several other Chinese products like liquid milk, yogurts, frozen desserts, powdered milk, cereal products, confectionaries, cheesecakes and biscuits, protein powders, cookies, coffee, sweets, pasta, and rice and some processed foodstuffs.

Subsequently, some other products originating from China such as ammonium bicarbonate, animal feed and animal feed ingredients, dried whole egg, fresh hen eggs, and non-dairy creamer were found contaminated with melamine. The manufacturing companies had to recall their products.

\section{Implications for international food safety}

Food contamination, whether accidental or intentional, has been a sad, recurrent theme throughout recorded history, going back some 8000 years. However, a new dimension has been added in this new millennium: globalization and international agribusiness allow problems with the food supply to spread around the planet that to very quickly. Now melamine is being discovered in other foods, which are turning up worldwide.

Melamine contamination of foodstuffs produced in China is an international public health crisis, and the full repercussions of this scandal may not be known for many years. In total, 47 countries received melaminecontaminated products. The different countries responded through a wide range of actions-from no action at all to the ban of all imports of milk and milk products from China. A number of countries banned or recalled foods suspected of containing melamine. However, questions still remain as to when and how to consider this incident under control. For many trading partner countries, it is difficult to assess the safety of future supplies and to decide on what basis to lift the restrictive measures imposed. For the Chinese authorities, demonstrating that the measures they have put in place will ensure an appropriate level of confidence in the future safety of food products is also posing a challenge.

Food Safety and Standards Authority of India issued an advisory (Advisory No.: 2/FSSAI/2008) to the state health authorities on monitoring melamine contamination of foods. In September 2008, FSSAI also imposed ban on import of Chinese milk and milk products, including chocolates and chocolate products and candies/confectionery/food preparations with milk and milk solids as ingredients from 
China and extended on yearly basis thereafter. Presently the ban is extended till June 23, 2016.

\section{Analysis}

The common methods for the determination of melamine in feed and food are liquid chromatography (LC), high performance liquid chromatography (HPLC), liquid chromatography/tandem mass spectrometry (LC/MS/MS), gas chromatography mass spectrometry (GC/MS) and gas chromatography/tandem mass spectrometry (GC/MS/MS). Melamine in milk and milk products is determined by HPLC-UV or DAD, HPLC-MS/MS and GC-MS or GCMS/MS with quantification limits of 2, 0.01, and $0.05 \mathrm{mg} / \mathrm{kg}$ respectively.

The methods using different approaches, such as enzyme-linked immunosorbent assay, electrophoresis, capillary electrophoresis, ultraviolet absorption, surface enhanced Raman spectroscopy, nuclear magnetic resonance spectroscopy, sweeping-micellar electrokinetic chromatography, direct analysis in real time with time-of-flight mass spectrometry, molecularly imprinted polymer film, chemiluminescence, electrochemical sensor, and optical biosensorsare reported. Recently, aptamer and colorimetric nanoparticles based assay giving visual detection of melamine is widely reported. It is also opined that since melamine is not metabolized in body and excreted unchanged in the urine, its estimation in urine may be a yardstick to check for melamine adulteration in food.

In conclusion, melamine was well known to only polymer chemists before 2007 . However, the scenario changed and versatile chemical of plastic industry figured as potential adulterant in protein rich food and emerged as serious threat to human health.
It is an unfortunate fact of chemistry that the combination of two relatively innocent chemicals can turned out toxic and create serious health hazards. This complex nature of toxicity may pose a challenge for traditional risk assessment methods, which are based on assessment of the toxicity of individual compound s. Now well-known example for synergistic toxicity is melaminecyanurate complex. Therefore, regulatory levels of melamine need to be re-considered for cases of co-exposure with cyanuric acid.

The adulteration of food and feed ingredients is of great concern not only due to the risk of economic losses that purchasers may incur, but also due to the potential health risks to the consumers. Protein concentrates are the main risk factor of food chain contamination with melamine and cyanuric acid. The tainted gluten is a potential source of melamine for human from vegetarian foods having high levels of gluten. Even high contamination of melamine in livestock feed can pose a serious health risk for population drinking milk. In particular, it should be considered the enrichment factor in powder milk used for infant formula and other human foods.

Kjeldahl method, the standard protein determination assays cannot differentiate between protein nitrogen and non-protein nitrogen. Adulteration of melamine in milk and milk products is not only related to external addition, but also to adulteration of animal feeds. Cows consuming melamine could present a serious health risk to consumers of milk and dairy products. The surveillance on raw material and animal feed production is strongly recommended to avoid human melamine intake by milk consumption. The exploitation of NPN compounds will continue to occur in future unless protein-specific analytical procedures are adopted. Approaches to mitigate future fraudulent or harmful adulteration of food 
protein ingredients, to protect public health and to facilitate trade will require the development and adoption of reliable, specific quantification of protein.

Food adulteration has been a recurrent theme throughout recorded history. However, a new dimension has been added in new millennium: globalization and international agribusiness allow problems with the food supply to spread around the planet that to very quickly. The melamine scandals of feed and food ingredients very well indicate that the consumers are highly vulnerable to quality risks in a global supply chain. Supply chains are extended by outsourcing and stretched by globalization, which greatly increase the complexity of supply network and decrease the visibility in risk and operation process. It is very difficult to manage and assure the product quality of such a multi-layer supply chain which has a low traceability of material origin. The tainted raw material produced in a poorly regulated market may cross national boundaries and be used in manufacturing processes for numerous products, Although final product manufacturing may be performed under highly regulated guidelines, once in the production chain, tainted raw materials is widely disseminated worldwide.

Toxicity from tainted foods is generally identified only when large numbers of people or animals are affected and numerous deaths result. An important step for regulatory agencies will be to develop more effective proactive approaches. The proactive product testing averts possible tragedies. The managing of outbreaks strongly depends on a well-structured food-safety system in which communication and access to information are key factors. Incidences of melamine out breaks and the rapid spread of the affected products worldwide has evidenced the need for a mechanism for coordination and information exchange linked food-safety activities.

\section{How to cite this article:}

Sachin S. Lad and Aparnathi, K.D. 2017. Melamine: A Monster in the Milk. Int.J.Curr.Microbiol.App.Sci. 6(4): 876-882. doi: https://doi.org/10.20546/ijcmas.2017.604.110 